\title{
The Promoter of the Human Interleukin-2 Gene Contains Two Octamer-Binding Sites and Is Partially Activated by the Expression of Oct-2
}

\author{
MARK P. KAMPS, ${ }^{1 *}$ LYNN CORCORAN,${ }^{1}$ JONATHAN H. LEBOWITZ,${ }^{2} \dagger$ AND DAVID BALTIMORE ${ }^{1.3}$ \\ Whitehead Institute for Biomedical Research, 9 Cambridge Center, Cambridge, Massachusetts $02142^{1}$; Massachusetts \\ Institute of Technology Center for Cancer Research, Cambridge, Massachusetts 02139²; and \\ The Rockefeller University, New York, New York $10021^{3}$
}

Received 7 March 1990/Accepted 15 June 1990

\begin{abstract}
The gene encoding interleukin-2 (IL-2) contains a sequence 52 to 326 nucleotides upstream of its transcriptional initiation site that promotes transcription in $T$ cells that have been activated by costimulation with tetradecanoyl phorbol myristyl acetate (TPA) and phytohemagglutinin (PHA). We found that the ubiquitous transcription factor, Oct-1, bound to two previously identified motifs within the human IL-2 enhancer, centered at nucleotides -74 and -251 . Each site in the IL-2 enhancer that bound Oct-1 in vitro was also required to achieve a maximal transcriptional response to TPA plus PHA in vivo. Point mutations within either the proximal or distal octamer sequences reduced the response of the enhancer to activation by 54 and $34 \%$, respectively. Because the murine T-cell line EL4 constitutively expresses Oct-2 and requires only TPA to induce transcription of the IL-2 gene, the effect of Oct-2 expression on activation of the IL-2 promoter in Jurkat $T$ cells was determined. Expression of Oct-2 potentiated transcription 13-fold in response to TPA plus PHA and permited the enhancer to respond to the single stimulus of TPA. Therefore, both the signal requirements and the magnitude of the transcription response of the IL-2 promoter can be modulated by Oct-2.
\end{abstract}

The gene encoding interleukin-2 (IL-2) is one of a family of genes whose transcription is induced by activation of $\mathrm{T}$ lymphocytes $(22,44)$. Although $\mathrm{T}$-cell activation is a complex process in vivo, involving the binding of antigen and costimulation by lymphokines $(19,26,28,41,43)$, activation of $\mathrm{T}$ cells in tissue culture can be accomplished by stimulation with phytohemagglutinin (PHA), which induces the same increase in intracellular free calcium as does the binding of antigen $(12,14,33,39,40)$, and tetradecanoyl phorbol myristyl acetate (TPA), which substitutes for lymphokines (40).

A fragment of the IL-2 promoter extending 52 to 326 nucleotides from the transcriptional initiation site functions as a T-cell-specific enhancer, strictly modulated by the combined stimuli of TPA plus PHA $(5,11)$. These sequences contain essential binding sites for the transcription factors NF- $\kappa B$ (32) and NFAT (34). Two additional factors, NFIL2-A, and NF-IL2-D, bind sequences in the IL-2 promoter centered at -74 and -251 (7; Fig. 1). When assayed by electrophoresis through polyacrylamide gels under native conditions, oligonucleotides containing these sequences cross-compete for the formation of a single complex, indicating that NF-IL2-A and NF-IL2-D are likely the same protein (6). Deletion of the sequences to which NF-IL2-A and NF-IL2-D bind results in a 95 and $59 \%$ reduction in the ability of the promoter to respond to stimulation in the context of an IL-2 promoter chloramphenicol acetyltransferase (CAT) construct, and multimers of a 30-base-pair (bp) sequence $(-65$ to -94$)$ containing the NF-IL2A site confer calcium responsiveness upon the fibrinogen promoter (6). In addition, coincident with T-cell activation, a major DNase I-hypersensitive site appears at $-85(36)$, whose formation is

\footnotetext{
* Corresponding author.

† Present address: Department of Biological Chemistry and Molecular Pharmacology, Harvard Medical School, Boston, MA 02115.
}

blocked if $\mathrm{T}$ cells are activated in the presence of cyclosporin A (36), a compound that inhibits the production of IL- 2 in T cells activated by PHA or antibodies against T3 (2). Consequently, proteins that bind this 30 -bp sequence are involved directly in the activation pathway. The close similarity between sequences in the NF-IL2-A- and NF-IL2-D-binding sites (ATGTAAAACA and ATGCAATTAA, respectively) and those of the canonical octamer sequence found in many transcription control systems (ATGCAAATNA) led us to investigate whether NF-IL2-A and NF-IL2-D are actually the octamer-binding protein, Oct-1.

The octamer sequence, ATGCAAAT, was originally discovered in the promoter of immunoglobulin genes $(7,29,30)$, and deletion analysis proved that the octamer motif is required for specific transcription in $B$ cells $(1,3,7,8,9,30)$. Octamer motifs also function as essential elements in the promoters of genes transcribed outside the B-lymphocytic lineage, such as those regulating the expression of histone $\mathrm{H} 2 \mathrm{~B}$ and the $\mathrm{U} 1$ and $\mathrm{U} 2$ small nuclear RNAs $(2,20,24,37)$. Although octamer-binding sites normally have the sequence ATGCAAATNA, closely related sequences also serve as octamer-binding sites; ATGCTAATGA, for instance, found in the promoter of the herpes simplex virus type 1 gene encoding IE110K, binds Oct-1 efficiently (27). In this report, we demonstrate that the cellular factors NF-IL2-A and NF-IL2-D are indistinguishable from Oct-1 and that their specific binding sites are important for the TPA- and PHAinducible properties of the IL-2 enhancer. We also investigate the effect of Oct-2, a second octamer-binding protein expressed mainly in $B$ lymphocytes, on the response of the IL-2 enhancer to TPA or TPA plus PHA.

\section{MATERIALS AND METHODS}

Preparation of nuclear extracts. Nuclear extracts were prepared according to the procedure outlined by Dignam et al. (4) and stored at $-80^{\circ} \mathrm{C}$. 


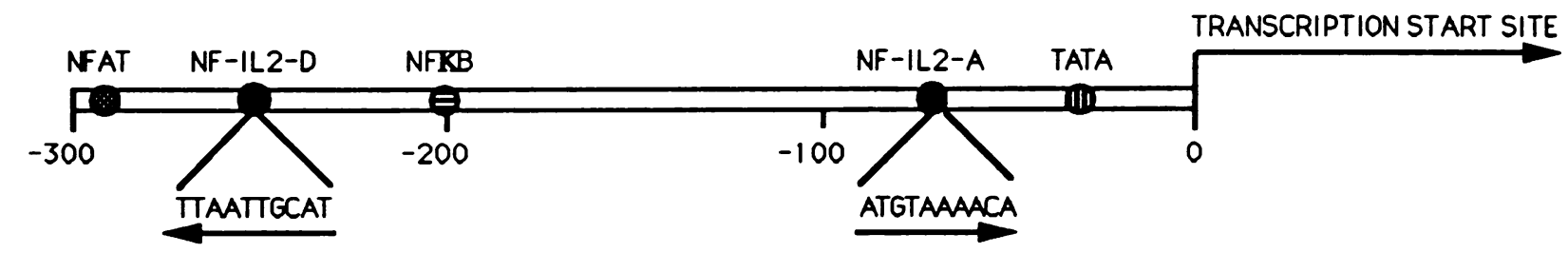

FIG. 1. Binding sites for transcription factors in a PHA-plus-TPA-responsive portion of the IL-2 promoter. Arrows indicate that octamer sequences are positioned in opposing orientations.

Gel mobility shift assays. At room temperature, $0.5 \mu \mathrm{g}$ of nuclear extract was incubated with $20 \mathrm{fmol}$ of probe in $20 \mu \mathrm{l}$ of a solution containing $3 \mu \mathrm{g}$ of poly(dI-dC), $2 \%$ glycerol, 1.0 $\mathrm{mM}$ dithiothreitol, $20 \mathrm{mM} \mathrm{NaCl}, 10 \mathrm{mM}$ Tris (pH 7.5), 1.0 mM EDTA, $30 \mu \mathrm{g}$ of bovine serum albumin, and $5 \%$ buffer $\mathrm{D}$ (20 mM N-2-hydroxyethylpiperazine- $N^{\prime}$-2-ethanesulfonic acid [HEPES; pH 7.9], 25\% glycerol, $0.42 \mathrm{M} \mathrm{NaCl}, 1.5 \mathrm{mM}$ $\mathrm{MgCl}_{2}, 0.2 \mathrm{mM}$ EDTA, $0.5 \mathrm{mM}$ phenylmethylsulfonyl fluoride, $0.1 \%$ aprotinin, $0.5 \mathrm{mM}$ dithiothreitol). The DNAprotein complexes were separated by electrophoresis through $4 \%$ acrylamide gels, using nondenaturing conditions and a buffer containing $6.8 \mathrm{mM}$ Tris (pH 7.5), $3.4 \mathrm{mM}$ sodium acetate, and $1.0 \mathrm{mM}$ EDTA. The rabbit anti-Oct-2 serum that blocked the formation of complexes containing octamer protein was prepared as described previously (16) against an Oct-2-protein A fusion protein designated PAOct-2 (17). A $0.5-\mu l$ volume of anti-Oct-2 was used per assay.

Glycerol gradient sedimentation. A $100-\mu$ l volume of nuclear extract from BJA/B cells $(6.0 \mathrm{mg} / \mathrm{ml})$ was diluted with $100 \mu$ l of buffer D containing no glycerol. The final concentration of glycerol was $10 \%$. This mixture was layered on a 5-ml glycerol gradient (15 to $30 \%$ ) formed in buffer D. The gradient was centrifuged at $40,000 \mathrm{rpm}$ in an SW50.1 rotor for $17 \mathrm{~h}$, and 20 fractions were isolated by dripping the contents from the bottom of the tube. The presence of Oct-2 was monitored by using the gel mobility shift assay, and fractions 8 and 9 contained $80 \%$ of the activity.

DNase I protection assays. DNase I footprinting (15) was performed by using $10 \mathrm{fmol}$ of probe and $1.2 \mu \mathrm{g}$ of poly(dIdC) per reaction. In reactions containing Oct- 2 , partially purified by centrifugation through a glycerol gradient, $25 \mu \mathrm{l}$ of fraction 8 or 9 was used. In those reactions containing recombinant Oct-2, 20 ng was used. All reactions were subjected to digestion with $5 \mathrm{ng}$ of DNase I on ice for $1 \mathrm{~min}$.

Methylation interference assays. Dimethyl sulfoxide was used to partially methylate ${ }^{32}$ P-end-labeled DNA (21), and the radioactive DNA fragment was used in the gel mobility shift assay. The DNA contained in the complexed and free pools was identified by autoradiography of the wet gel, which was wrapped in Saran wrap. These bands were excised from the gel and electroeluted for $1.0 \mathrm{~h}$ to recover the DNA. The eluted DNA was extracted consecutively with phenol and then with phenol-chloroform (1:1) and was recovered by precipitation with 2.5 volumes of ethanol. The pellet was redissolved in $100 \mu$ l of $1.0 \mathrm{M}$ piperidine, incubated at $90^{\circ} \mathrm{C}$ for $30 \mathrm{~min}$, and lyophilized. The products were analyzed by electrophoresis through a $12 \%$ polyacrylamide gel containing $8.0 \mathrm{M}$ urea.

Transfection and stimulation of Jurkat $\mathbf{T}$ cells. Jurkat $\mathrm{T}$ cells were grown in RPMI medium containing $10 \%$ fetal bovine serum. DEAE-dextran-mediated transfection (13) was used to introduce plasmid DNA. In all cases, a $15-\mu \mathrm{g} / \mathrm{ml}$ concentration of either pIL2CAT or pIL2fosCAT was used. The cells were stimulated with either TPA $(50 \mathrm{ng} / \mathrm{ml})$ alone or with TPA $(50 \mathrm{ng} / \mathrm{ml})$ and PHA $(2 \mu \mathrm{g} / \mathrm{ml})$ for $10 \mathrm{~h}$. CAT activity in cellular extracts was determined by measuring catalytic transfer of the acetyl group from $\left[{ }^{14} \mathrm{C}\right]$ acetyl coenzyme A to chloramphenicol. The amount of extract and duration of incubation with substrate varied as indicated in the figure legends. Reaction products were resolved by ascending chromatography, and ${ }^{14} \mathrm{C}$-acetylated chloramphenicol was quantitated by scintillation spectroscopy. Background in the CAT assays included both acetylated chloramphenicol and impurities in the $\left[{ }^{14} \mathrm{C}\right]$ chloramphenicol that comigrated with acetylated chloramphenicol.

Mutagenesis of pIL2fosCAT. The technique of gapped heteroduplex mutagenesis (18) was used to make specific nucleotide changes in both the proximal and distal IL-2 octamer motifs. Oligonucleotides TCGACATATGTGTAA GGCCTAAAACATTTTGAC and TCGACAGCTCTAAT TCATGCAATTAACGCCTTC were used respectively for creating the mutants at these sites.

\section{RESULTS}

Two sequences in the IL-2 promoter bind cellular proteins that exhibit electrophoretic properties identical to those of Oct-1, Oct-2, and Oct-2B. A variety of techniques were used to demonstrate that octamer proteins bind to two sites in the IL-2 promoter. First, complexes formed between IL-2 enhancer DNA and proteins extracted from purified nuclei were analyzed by separation through $4 \%$ polyacrylamide gels under nondenaturing conditions. The mobility of protein-DNA complexes formed with probes from the IL-2 promoter was compared with the mobility of those formed with a 145-bp fragment of the immunoglobulin heavy-chain promoter, designated $\mathrm{V}_{\mathbf{H}}$, which contains a consensus octamer motif. The $V_{H}$ probe formed a complex with Oct-1 in the presence of nuclear extracts from both the human T-cell line, Jurkat, and the human carcinoma line, HeLa, and with Oct-1, Oct-2, and Oct-2B in nuclear extracts from the mature human B-cell lymphoma cell line, BJA/B (Fig. 2A, lanes 1, 4, and 7). Probes containing IL-2 promoter sequences spanning -60 to -145 bp (proximal IL-2 probe; Fig. 2B) and -235 to -350 (distal IL-2 probe; Fig. 2C) each formed a complex (designated 1 ; lanes 1 and 7) with a protein in nuclear extracts from Jurkat and HeLa cells that appeared indistinguishable from that formed between Oct-1 and the $V_{H}$ probe. Likewise, when incubated with extracts from BJA/B nuclei, the proximal and distal IL-2 probes formed complexes 1, 2, and 3, which comigrated with the Oct-1, Oct-2, and Oct-2B complexes (lanes 4). Each complex behaved as if it contained an octamer-binding protein because the formation of each was inhibited by inclusion of $20 \mathrm{ng}$ of an oligonucleotide containing the octamer motif (CTTAATAATTTGCATAC CCTCAGATC; lanes 2 and 5) but not by inclusion of $66 \mathrm{ng}$ of a nonspecific oligonucleotide (CCTCCAAAGAGTCAT CAGAAGAGGAAAT; lanes 3 and 6). These data suggested that octamer-binding proteins were capable of recognizing at 


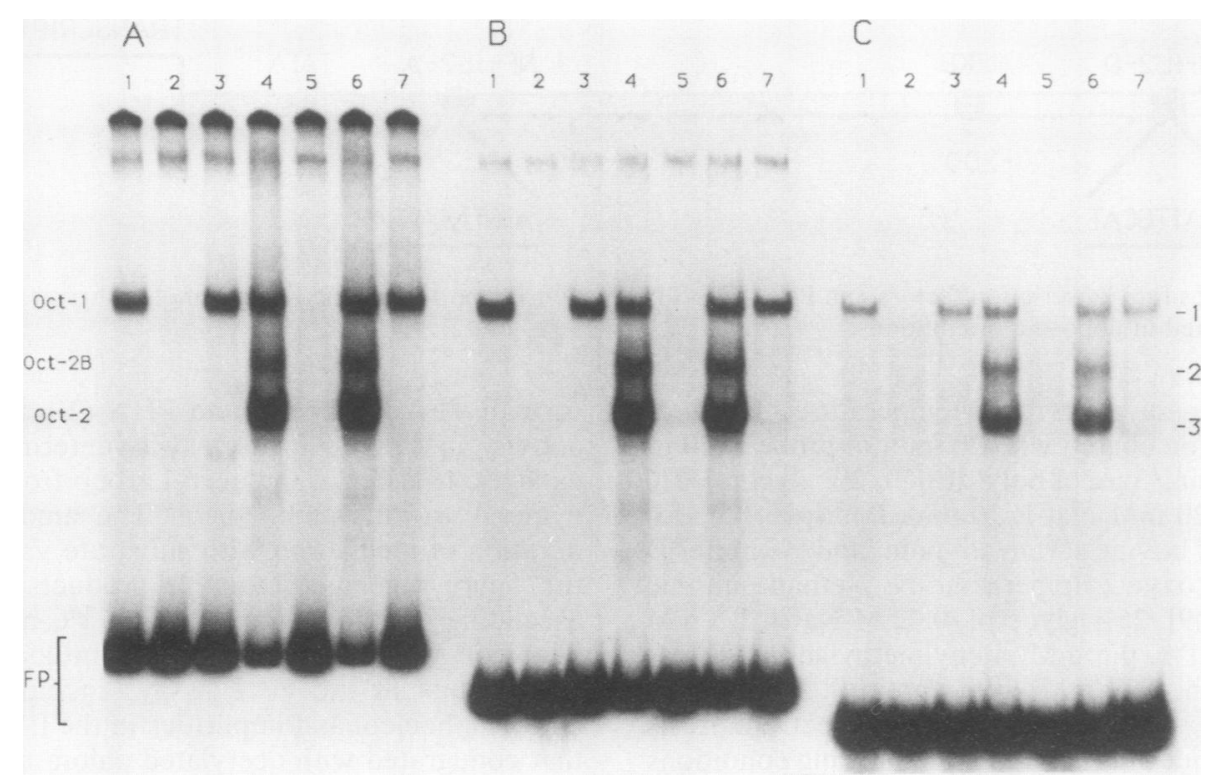

FIG. 2. Analysis of complexes that form with enhancer sequences from the IL-2 gene. Gel mobility shift assays were performed by using the $V_{H}$ probe $(A)$, the proximal IL-2 probe (B), and the distal IL-2 probe (C). The specific activity of each probe was approximately 450 $\mu \mathrm{Ci} / \mathrm{mmol}(1,000 \mathrm{cpm} / \mathrm{fmol})$. Complexes were formed by using $500 \mu \mathrm{g}$ of nuclear extract from Jurkat T cells (lanes 1 to 3 ), $120 \mu \mathrm{g}$ of nuclear extract from BJA/B cells (lanes 4 to 6), and $500 \mu \mathrm{g}$ of nuclear extract from HeLa cells (lanes 7), and the formation of complexes was challenged by inclusion of $20 \mathrm{ng}$ of octamer oligonucleotide (lanes 2 and 5) or nonspecific oligonucleotide (lanes 3 and 6). FP, Free probe.

least two sites in the enhancer of the IL-2 gene. Based on the amount of complex formed in this assay and the similar specific activities of the three probes used, the predicted affinities of each site for octamer-binding proteins would be $\mathrm{V}_{\mathrm{H}}$ probe $>$ IL-2 proximal probe $>$ IL-2 distal probe.

Recombinant Oct-2 binds at least two sites in the IL-2 promoter. The ability of an octamer-binding protein to interact directly with the proximal and distal IL-2 probes was tested by incubation with Oct- 2 protein, synthesized in bacteria as a fusion with protein A (17). The Oct-2 protein was used here for convenience; Oct-1 and Oct- 2 have indistinguishable binding specificities. The $\mathrm{V}_{\mathbf{H}}$ probe, as well as both the proximal and distal IL-2 probes, formed complexes with recombinant Oct-2 (Fig. 3, lanes 1, 4, and 7) that were dissociated by inclusion of $20 \mathrm{ng}$ of octamer oligonucleotide (lanes 2, 5, and 8), but not by addition of $66 \mathrm{ng}$ of nonspecific oligonucleotide (lanes 3,6 , and 9), to the incubation buffer. A probe containing a high-affinity site for the transcription factor NF-kB did not form complexes with recombinant Oct-2 (lanes 10 to 12 ). This assay proved that Oct- 2 can bind to at least one site in both the proximal and distal IL-2 probes and again suggested that the affinity of the sites for recombinant octamer-binding protein assumed the order $\mathrm{V}_{\mathbf{H}}$ probe $>$ IL-2 proximal probe $>$ IL-2 distal probe.

Antibodies to Oct-2 specifically inhibit complex formation. The fact that recombinant Oct-2 bound specifically to sites within two fragments of the IL-2 enhancer implied, but did not prove, that native octamer-binding proteins in nuclear extracts also bound these sites. This proof was obtained by demonstrating that the factors in $\mathrm{BJA} / \mathrm{B}$ nuclear extract that bind to the proximal and distal IL-2 probes reacted with antibody against Oct-2 (16). Antibody to Oct-2 inhibited the formation of Oct-1, Oct-2, and Oct-2B complexes with $V_{\mathbf{H}}$ (Fig. 4, lanes 2 and 3 ) as well as of the corresponding complexes formed with each IL-2 probe (Fig. 4B and C, lanes 2 and 3). Nonspecific antibodies had no effect on the formation of these complexes (lanes 4). The antibodies did not cause an increase in the mobility of octamer proteins bound to DNA; rather, they blocked the interaction between DNA and the octamer-binding proteins, indicating that they react with epitopes in or near the DNA-binding domain or, alternatively, behaved as noncompetitive inhibitors.

Methylation interference and DNase I protection. The technique of methylation interference was used to determine the exact protein-DNA contact points in the complex formed

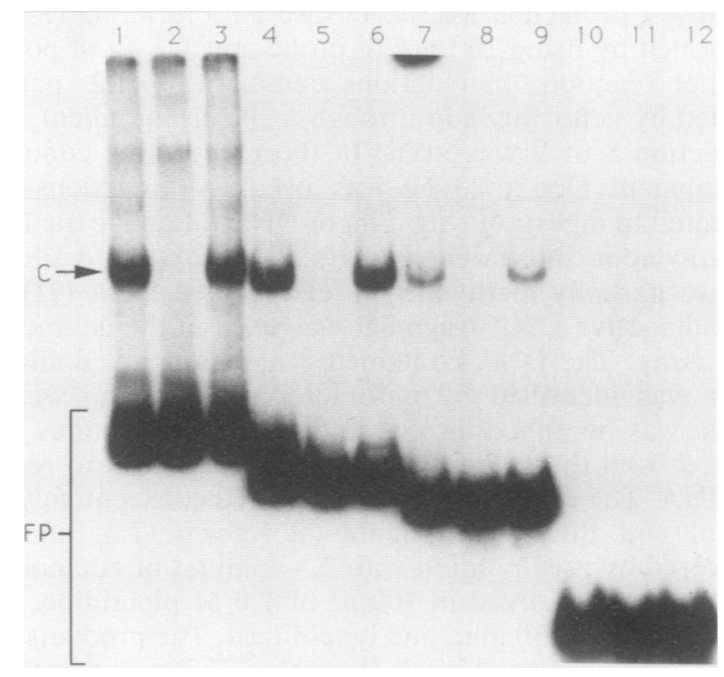

FIG. 3. Complex formation with use of recombinant Oct-2. Gel mobility shift assays were performed by using the $V_{H}$ probe (lanes 1 to 3 ), the proximal IL-2 probe (lanes 4 to 6), the distal IL-2 probe (lanes 7 to 9), and a probe containing the motif bound by NF-kB (lanes 10 to 12). Lanes 2, 5, 8, and 11 contain $20 \mathrm{ng}$ of octamer oligonucleotide; lanes $3,6,9$, and 12 contain $66 \mathrm{ng}$ of nonspecific oligonucleotide. $\mathrm{C}$, The location at which the complex containing recombinant Oct-2 migrates; FP, free probe. 


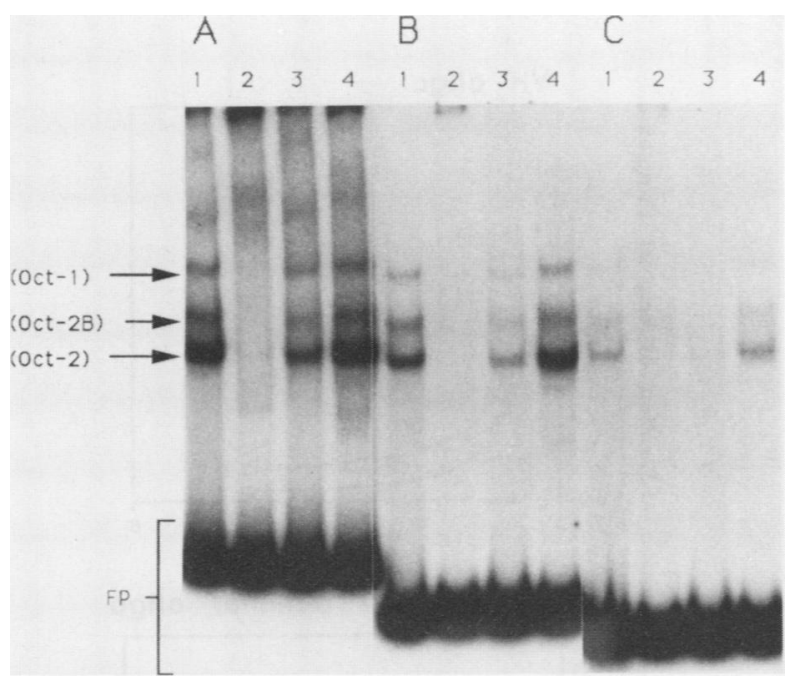

FIG. 4. Effect of anti-Oct-2 serum on complex formation. Gel mobility shift assays were performed by using $120 \mathrm{ng}$ of nuclear extract from BJA/B cells (all lanes) in the presence of $0.5 \mu$ l (lanes 2) and $0.1 \mu \mathrm{l}$ (lanes 3 ) of anti-Oct-2 serum or $0.5 \mu \mathrm{l}$ of a control antiserum, specific to the Abelson tyrosine protein kinase (lanes 4). (A) $\mathrm{V}_{\mathrm{H}}$ probe; (B) proximal IL-2 probe; (C) distal IL-2 probe. with the proximal IL-2 probe. DNA methylated at guanine residues on either strand of the sequence ATGTAAAACA $(-78$ to -69$)$, as well as at the intervening adenine residues, was excluded from complex formation by Oct-1 protein (Fig. $5 \mathrm{~A})$. This sequence varies at a single position when compared with the octamer consensus sequence, ATGCA AATNA, derived from analysis of octamer motifs in immunoglobulin promoters and heavy-chain enhancers. The fact that DNA molecules containing these methylated residues were quantitatively excluded from the Oct-1 complex demonstrates that this is the only site bound by Oct-1 in the probe. The location of this sequence is fully contained within the binding site for NF-IL2-A, previously defined by DNase I protection, indicating that the footprint observed over this sequence is, at least in part, a consequence of the binding of Oct-1. The low abundance of the Oct-1-containing complex that formed with the distal IL-2 probe precluded conclusive analysis of this site by methylation interference.

If the sequences protected by NF-IL2-D, as well as by NF-IL2-A, complex with octamer-binding proteins, then recombinant Oct-2 produced in bacteria should bind each site and protect exactly the same nucleotides as are protected in the footprints seen using nuclear extracts. In a DNase I protection assay, recombinant Oct- 2 bound exactly the same two sites that were protected by proteins extracted from BJA/B nuclei (Fig. 5B). The boundaries formed by
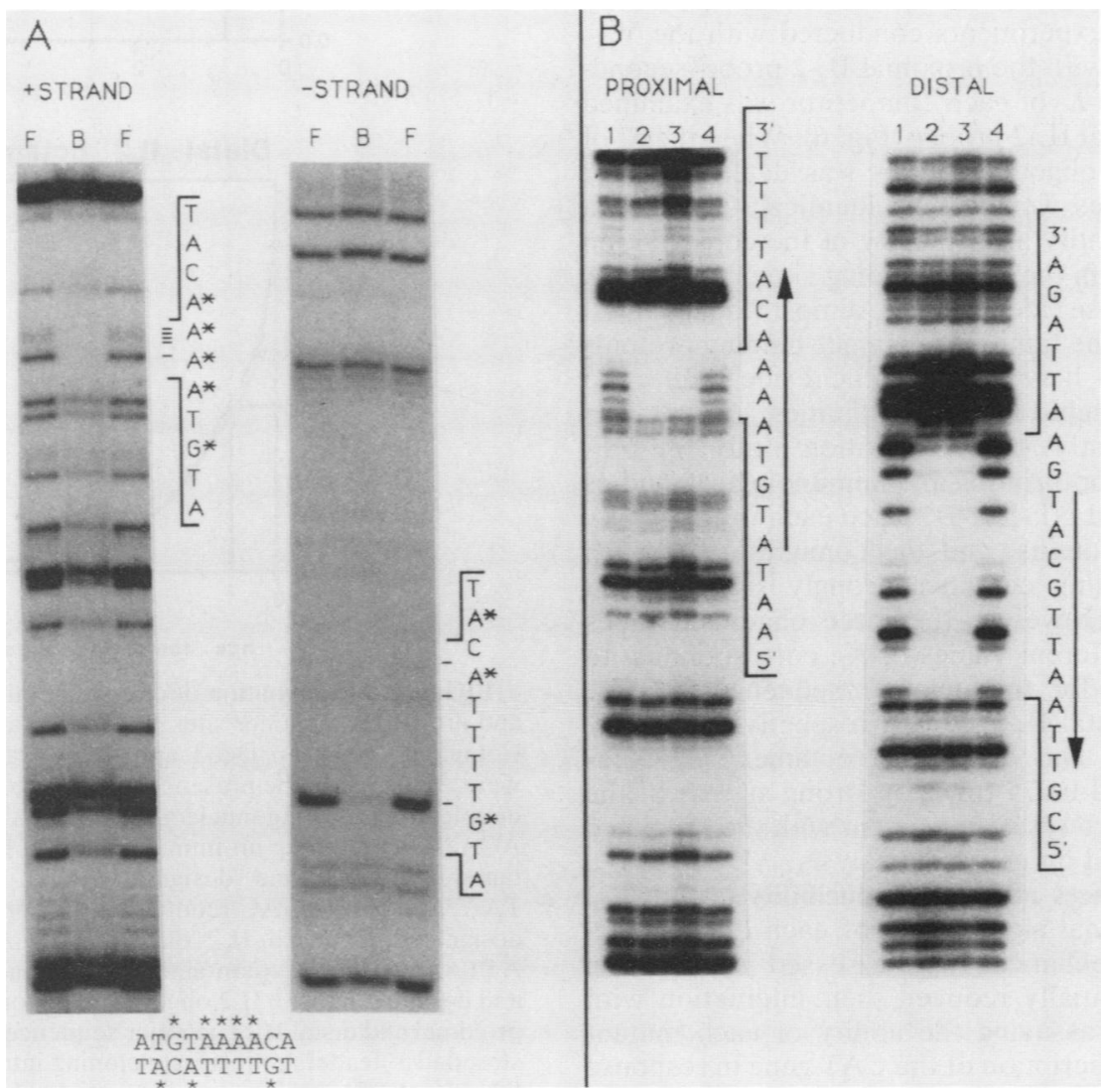

FIG. 5. Determination of the binding sites of the octamer proteins in IL-2 sequences. (A) Pattern of methylated nucleotides in the plus or minus strands of probes purified from the bound (B) or free (F) populations of complex 1, formed by using Jurkat nuclear extract. Dashes designate the positions of methylated residues excluded from the bound probe; asterisks mark the locations of these residues in the DNA sequence. (B) Patterns of DNase I cleavage of the proximal and distal IL-2 probes assayed in the presence of $20 \mu \mathrm{g}$ of bovine serum albumin (lanes 1 and 4), $20 \mathrm{ng}$ of recombinant Oct-2 protein (lanes 2), or $25 \mu \mathrm{l}$ of glycerol gradient-purified activity (see Materials and Methods) from BJA/B cells (lanes 3). 
protection with either recombinant Oct- 2 or with the activity from partially purified BJA/B nuclear extract were likewise identical. This experiment demonstrated that the activity in nuclear extracts that protects each of these sites is octamer protein. If total nuclear extracts were used, the $5^{\prime}$ boundary of the proximal octamer footprint was extended, suggesting that Oct-1 plus another cellular factor bind adjacent sites in this sequence. Nuclear extracts purified by affinity to heparin exhibited a much reduced footprint over the octamer sequence and a much stronger footprint over the immediate $5^{\prime}$ region (data not shown). The $5^{\prime}$ footprint was observed in extracts from Jurkat $\mathrm{T}$ cells as well as from HeLa cells and is therefore likely to be caused by a ubiquitous transcription factor.

Relative affinities of octamer sites. Oligonucleotides containing the $\mathrm{V}_{\mathbf{H}}$, IL-2 proximal, and IL-2 distal octamer sequences were used to compete with the $\mathrm{V}_{\mathbf{H}}$ and proximal IL-2 probes for binding to NF-IL2-A and Oct-1, respectively. If Oct- 1 binds each probe, then an oligonucleotide competitor should exhibit equivalent half-maximal inhibition on complex formation $\left(K_{i}\right)$ between Oct-1 and any octamercontaining probe, regardless of the affinity of the octamer sequence contained within that oligonucleotide. In similar fashion, since the $K_{i}$ of each oligonucleotide is a unique reflection of its affinity for the DNA-binding site of Oct-1, oligonucleotides having strong or weak affinities should exhibit parallel values of $K_{i}$ for any two octamer-containing probes. If, however, a protein other than Oct-1 bound this motif, the $K_{i}$ for a single oligonucleotide would likely vary between competition experiments conducted with the $\mathrm{V}_{\mathrm{H}^{-}}$ Oct-1 interaction and with the proximal IL-2 probe-secondfactor interaction. The $K_{i}$ of each competitor was examined for the $\mathrm{V}_{\mathrm{H}}$ and proximal IL-2 probes (Fig. 6). When the $K_{i}$ of any one of the three oligonucleotides was determined for both probes, the values were almost identical. These data suggested that the identity and stability of the constellation of amino acids that form the DNA-binding site of NF-IL2-A and Oct-1 are likewise identical or almost identical. If different members of the family of octamer-binding proteins have identical contacts between amino acid side chains and DNA, they could exhibit identical affinities for octamer sequences. Consequently, the competition study for NFIL2-A, as well as the footprinting and immunological studies for both NF-IL2-A and NF-IL2-D, place each in the family of octamer-binding proteins, and the comigration of each with an Oct-1-containing complex strongly suggests that each is Oct-1 itself. However, the three oligonucleotides exhibited distinctly different values of $K_{i}$, corresponding to $1.2,1.9$, and $16 \mathrm{nM}$ for the octamer sequences in $\mathrm{V}_{\mathbf{H}}$, proximal IL-2, and distal IL-2 DNAs, respectively. Consequently, the proximal and distal IL-2 octamer sequences have affinities 0.63 and 0.075 times as strong as that of the $V_{H}$ octamer sequence, a result consistent with the predicted order of affinities based on gel shift analysis.

Both octamer sequences affect the inducibility of the IL-2 enhancer. The functional significance of each octamer sequence in the IL-2 enhancer was assessed by creating mutations that substantially reduced their interaction with octamer proteins and assaying the ability of each mutant enhancer to direct transcription of the CAT gene in response to treatment of transfected cells with TPA plus PHA. The vector pIL2fosCAT was created to test the normal activity of the IL-2 enhancer; it contains residues -325 to -51 of the IL-2 promoter fused to nucleotides -56 to +112 of the fos promoter, which is followed by the CAT gene. As first reported by Durand et al. (6), these IL-2 enhancer sequences
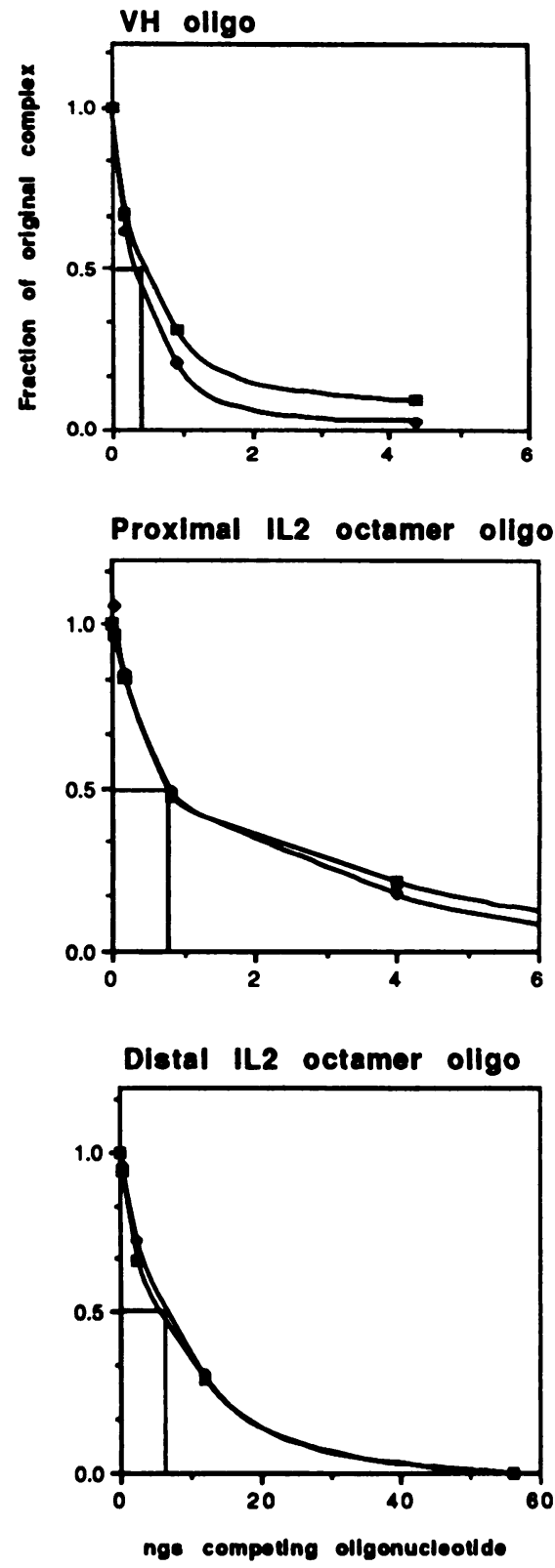

FIG. 6. Determination of relative affinities between the proximal and distal IL-2 octamer sites, the $\mathrm{V}_{\mathrm{H}}$ octamer sequence, and Oct-1. Complexes between Oct-1 and the $\mathrm{V}_{\mathrm{H}}$ and proximal IL-2 probes were measured in the presence of a $0.2-$ to $55-\mathrm{ng} / \mathrm{ml}$ concentration of double-stranded oligonucleotide CTTAATAATTTGCATACCCTC AGATC (containing an immunoglobulin heavy-chain enhancer octamer sequence and designated VH), CATATGTGTAAGGCC TAAAACATTTTGAC (containing the proximal IL-2 octamer and designated proximal IL2 oligo), and CAGCTCTAATTCATGCA ATTAACGCCTTC (containing the distal IL-2 octamer sequence and designated distal IL2 oligo). The oligonucleotides containing the proximal and distal IL-2 octamer sequences contained TCGA singlestranded 5' leaders to facilitate cloning into $\mathrm{XhoI}$ and SalI sites. The DNA-protein complexes were separated by electrophoresis through $4 \%$ nondenaturing polyacrylamide gels, and the radioactivity in the Oct-1 complex was quantitated by scintillation counting. Symbols: $\boldsymbol{\square}$, values obtained with the $\mathrm{V}_{\mathrm{H}}$ probe; $\boldsymbol{O}$, values obtained with the proximal IL-2 probe. 


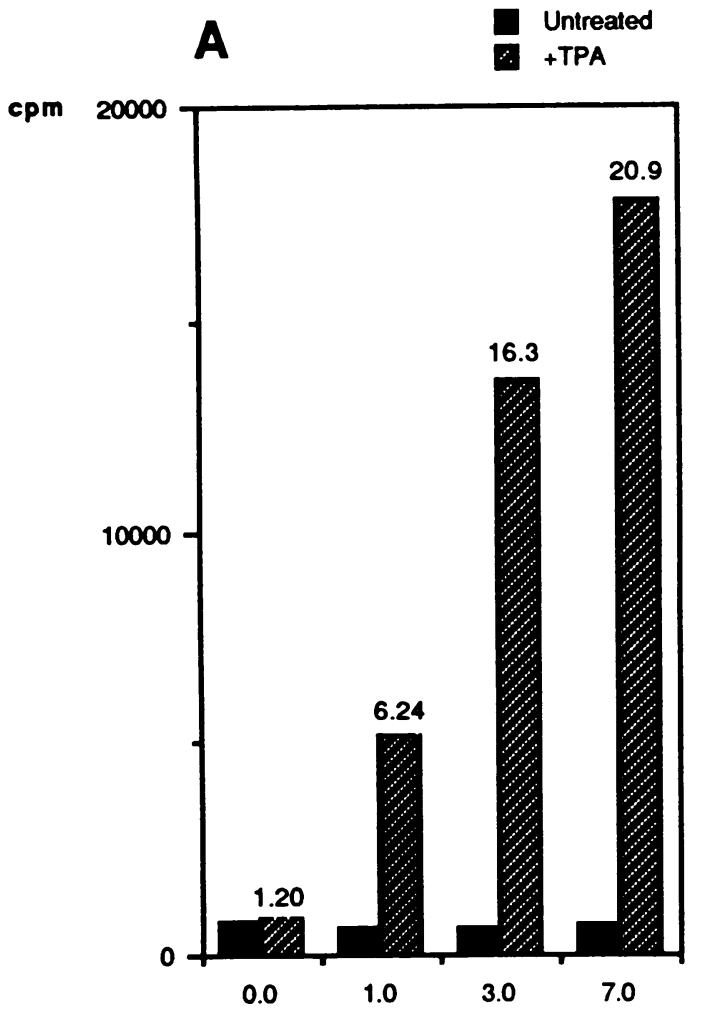

ug/ml Oct-2 expression plasmid added

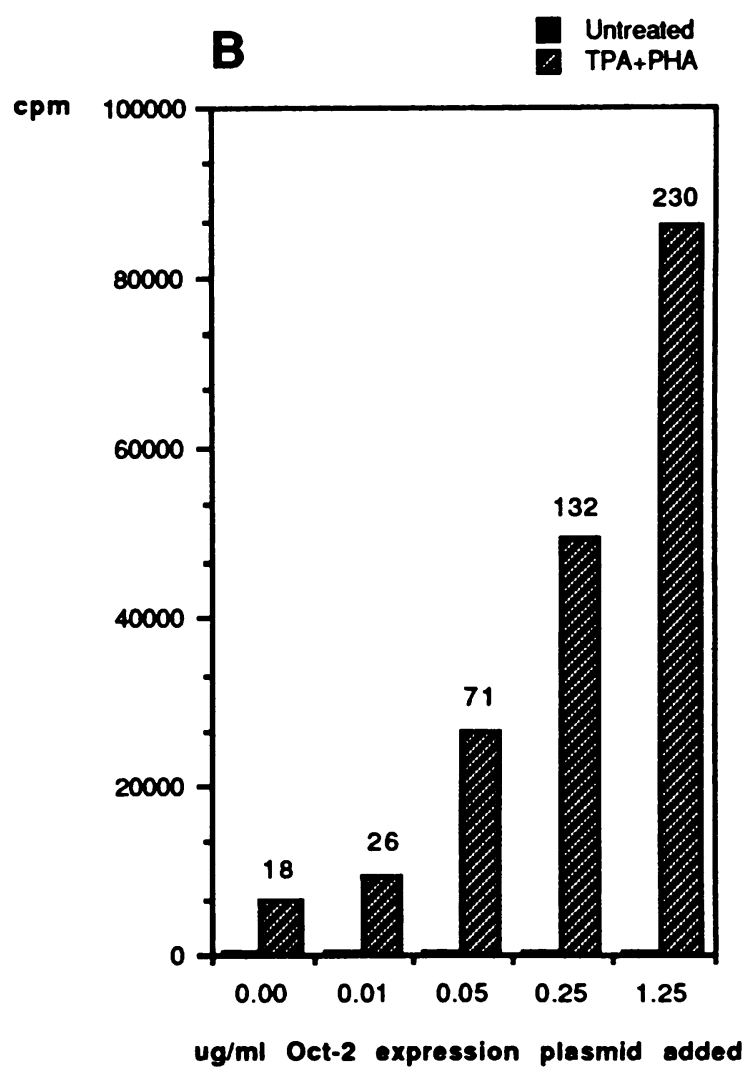

ug/ml Oct-2 expression plasmid added

FIG. 7. Determination of the effect of Oct-2 expression on stimulation of the IL-2 enhancer by TPA and by TPA plus PHA. Jurkat T cells were transfected with $15 \mu \mathrm{g}$ of pIL2CAT per ml. The amount of cotransfected Oct-2 expression plasmid is designated below the vertical bars and varied from 0.01 to $7.0 \mu \mathrm{g} / \mathrm{ml}$. Numbers above the bars represent the stimulation above control values for that set of conditions. In panel A, cells were stimulated with TPA alone, $80 \mu \mathrm{g}$ of extract was used for CAT assays, and incubation with substrate was allowed to proceed for $2.0 \mathrm{~h}$. In panel B, cells were stimulated with TPA plus PHA, $20 \mu \mathrm{g}$ of cellular extract was used, and the incubation time was $1.0 \mathrm{~h}$.

directed TPA-plus-PHA-dependent CAT transcription. Three point mutations were introduced into in each octanucleotide motif in pIL2fosCAT. The mutation at the proximal site converted the sequence ATGTAAAACA to GCC TAAAACA, and that at the distal site converted the sequence ATGCAATTAA to CGGAAATTAA. As a consequence of mutation, the binding of Oct-1 to the proximal site was reduced at least 50 -fold, and that to the distal site was reduced at least 10 -fold when assayed by gel mobility shift analysis. These mutations in the proximal and distal octamer sites diminished the response of the IL-2 enhancer to TPA plus PHA by 54 and 34\%, respectively (data not shown). Thus, each site is functionally important but neither is absolutely required.

Expression of Oct-2 permits induction of the IL-2 promoter by TPA alone and potentiates induction by TPA plus PHA. By contrast to Jurkat $\mathrm{T}$ cells, the mouse T-cell line EL4 expresses large quantities of Oct-2 in addition to Oct-1 $(38 ; \mathrm{L}$. Corcoran, unpublished observation). EL4 cells also differ from Jurkat cells in their ability to induce efficient IL-2 gene transcription in response to TPA alone (10). One reason why stimulation of the IL-2 gene in EL4 cells might be accomplished in the absence of the PHA-mediated signal is that Oct-2 substitutes for this signal, possibly by binding directly to the IL-2 octamer sites normally occupied by Oct-1. By comparison with the distal octamer sequence in the human IL-2 promoter (ATGCAATTAA), the corresponding sequence of the murine IL-2 promoter, ATACAATGAA, differs at nucleotides 3 and 8 and is not bound by nuclear factors when analyzed by a DNase I protection assay (32). However, the sequence of the proximal octamer motif is identical in the promoters of both species. A large footprint encompassing $31 \mathrm{bp}$ containing the proximal octamer sequence has been observed in DNase I footprinting studies of the murine IL-2 promoter (32); consequently, if Oct- 2 bound directly to the murine promoter, it would likely do so at the proximal site. To determine whether expression of Oct-2 would alter the induction of expression from the human IL-2 promoter, we constructed a second vector, pIL2CAT, which contains residues -550 to +51 of the IL-2 promoter followed by the CAT gene. In Jurkat $T$ cells, transcription of pIL2CAT was stimulated 1.2-fold by TPA (0.2-fold increase over background; Fig. 7A). TPA-stimulated transcription of pIL2CAT was then tested in the presence of a cotransfected Oct-2 expression plasmid (23; Fig. 7A). Cotransfection of the Oct-2 expression vector with pIL2CAT resulted in a 17-fold increase (1.2 to 20.9) in TPA-mediated stimulation of transcription, whereas the basal level of transcription from pIL2CAT was unaffected. Under these assay conditions, cells transfected with pIL2CAT and stimulated with TPA plus PHA produced a 140-fold induction $(n=3)$ in CAT activity. Therefore, cells containing Oct- 2 were capable of transcribing the IL-2 gene in response to TPA treatment at a level $12 \%$ that induced by both TPA plus PHA. Clearly, Oct-2 did not substitute fully for the PHA-responsive pathway.

To determine whether Oct-2 substituted for a PHA-induced signal or instead evoked a superinduction of transcrip- 
tion by synergizing with normal cellular stimuli, we tested whether Oct-2 expression had multiplicative effects on induction by TPA plus PHA. Cotransfection of the Oct-2 expression vector with pIL2CAT synergized strongly with induction by TPA plus PHA, increasing stimulated transcription 13-fold (Fig. 7B). Consequently, Oct-2 enhances transcription through a mechanism independent of those utilized by TPA plus PHA. Because of the powerful transcriptional effect mediated by Oct-2, we found it necessary to reduce the amount of extract (fourfold) and the duration of the assay (twofold) to maintain the linearity of the assay. Because a large proportion of the control radioactivity measured in extracts from uninduced cells arises from impurities in the $\left[{ }^{14} \mathrm{C}\right]$ chloramphenicol, the control values remained essentially the same while the activity values were reduced by a factor of 8. Consequently, the calculated values for transcriptional induction by TPA and PHA were reduced from 140 -fold to 18 -fold under these conditions. When CAT activity was measured under standard conditions $(80 \mu \mathrm{g}$ of cell extract and a 2-h incubation), extracts from cells cotransfected with pIL2CAT and the Oct- 2 expression vector and stimulated with TPA plus PHA yielded values well beyond the linear range of the assay $(>95 \%$ conversion to acetylated chloramphenicol). However, to determine whether cotransfection of the Oct-2 expression plasmid affected the efficiency of pIL2CAT uptake, standard conditions were used to examine background CAT activity contained in cytosolic extract derived from unstimulated cells. Regardless of the concentration of cotransfected Oct-2 expression plasmid, background CAT activity did not vary, indicating that inclusion of the Oct- 2 expression plasmid did not affect the transfection efficiency of pIL2CAT.

\section{DISCUSSION}

These data demonstrate that the nuclear factors NF-IL2-A and NF-IL2-D are almost certainly Oct-1, based on the facts that their binding affinities and specificities for octamercontaining DNA fragments are identical to those of Oct-1 and that they are each physically and immunologically indistinguishable from Oct- 1 . The sites bound by Oct-1 in the IL-2 promoter were localized by methylation interference and footprint analysis to the proximal sequence $5^{\prime}$-ATGT AAAACA-3' $(-69$ to -78$)$ and the distal sequence $5^{\prime}$ TTAATTGCAT-3' $(-247$ to -256$)$. Mutation of each site resulted in a moderate inhibition of transcriptional stimulation by TPA plus PHA, indicating that each site contributes to the positive regulation of the IL-2 gene, but neither is essential for activation in Jurkat T cells by TPA plus PHA when transcription is driven by the -51 to -321 IL-2 enhancer. It is also possible that the biological induction of the IL-2 gene in vivo requires octamer-binding proteins, whereas during induction by TPA plus PHA, the octamer motifs are less important. The elimination of single factorbinding sites from complex enhancers does, however, often result in marginal effects on transcription. For instance, mutation of any of the E-box motifs or the octamer site within the murine heavy-chain $\mu 700$ enhancer fragment reduces its ability to enhance transcription in $B$ cells by less than $50 \%$ in each case (18). During the preparation of this report, Shibuya and Taniguchi (35) reported that each of these sites may bind octamer or octamerlike proteins. This suggestion has proven correct in light of our results.

In Jurkat $T$ cells, which normally express only Oct-1, the transcriptional response of the IL-2 promoter to either TPA or TPA plus PHA was potentiated by expression of Oct-2.
Oct-2 expression permitted a transcriptional response to TPA alone; however, its presence did not interfere with the normal cellular PHA-responsive pathway, because combined treatment with TPA plus PHA was much more effective in inducing transcription in the presence of Oct-2 than was treatment with TPA alone. In this sense, the effects of introducing Oct- 2 by plasmid transfection or of removing the Oct-1-binding site by mutagenesis had parallel effects: both changed the magnitude of TPA-plus-PHA-stimulated transcription without altering the synergistic effect of both compounds. Previous studies have demonstrated that Oct-1 and Oct- 2 have very different effects on transcription. In B cells, which contain Oct-2, transcription of transfected genes can be activated by inserting octamer sequences $5^{\prime}$ of their transcription initiation sites (42). Although these same DNA constructs are transcriptionally inactive in cells containing Oct-1 but not Oct-2, transcription can be induced by the coexpression of a plasmid encoding Oct-2 (23). This effect is thought to be mediated by direct binding of Oct- 2 at the inserted octamer site. Therefore, one explanation that accounts for the mechanism by which Oct-2 affects transcription through the IL-2 enhancer is that Oct-2 binds directly to the proximal and distal octamer sites. Since the proximal site is contained within a PHA-responsive 30-bp sequence, binding of Oct- 2 at this location could provide a constitutive activation function, partially circumventing the requirement for PHA and causing the IL-2 promoter to become responsive to TPA alone. A second possibility is that Oct-2 titrates out a PHA-responsive repressor without binding the IL-2 promoter sequences directly, thereby permitting activation by TPA alone. Finally, Oct- 2 may activate transcription of other genes, whose protein products circumvent the absolute requirement for the signal induced by PHA. Regardless of the manner by which Oct-2 affects transcription from the IL-2 promoter, these data suggest that at least part of the ability of the IL-2 promoter to be induced by TPA alone in EL4 cells is a consequence of the high level of Oct- 2 that is expressed in these cells.

The stimulatory effect of Oct- 2 on IL-2 promoter-mediated expression was not evident in the absence of either TPA or PHA. Consequently, the IL-2 promoter may also bind a repressor that requires a TPA-mediated cellular signal for derepression and is dominant to the activating function of Oct-2.

In contrast to mouse EL4 cells, human Jurkat $T$ cells contain no Oct-2 protein, as assayed by gel mobility shift analysis either before or after stimulation with TPA plus PHA (M. Kamps, unpublished data). Oct-2 is therefore unlikely to be involved in T-cell activation by TPA plus PHA in these cells; however, we cannot eliminate the possibility that Oct- 2 is induced by mediators of T-cell activation in vivo. Although evidence supporting a normal role of Oct- 2 in T-cell proliferation is lacking, constitutive expression of Oct-2 in the human T-cell line Molt-4 (31) is implicated in the abnormal expression of immunoglobulin genes in these cells. In this context, it is possible that cellular transformation as well is facilitated by expression of Oct-2. For instance, in light of our evidence that Oct- 2 can potentiate the production of IL-2, which induces the proliferation of quiescent T cells, mutations that lead to the expression of Oct- 2 might represent one of multiple genetic lesions required to activate constitutive transcription of the IL-2 gene, producing a $\mathrm{T}$-cell leukemia via autocrine growth stimulation.

In contrast to these results and those of Durand et al. (6), the proximal IL-2 octamer site itself was found to behave as a transcriptional repressor in CAT vectors containing the 
simian virus 40 enhancer, positioned $5^{\prime}$ to the IL-2 promoter (25). It is likely, however, that mutation of the proximal octamer site in these vectors, which increased the basal levels of CAT expression in $\mathrm{T}$ cells, did so by permitting more efficient readthrough transcription from cryptic initiation sites in the simian virus 40 enhancer rather than by allowing increased transcription from the normal start site. Indeed, using constructs containing the CAT gene under control of the IL-2 promoter alone, Zhang and Nabel find that mutation of the proximal octamer site diminishes substantially the ability of the construct to stimulate transcription in response to the addition of TPA and PHA (L. Zhang and $G$. Nabel, personal communication). Our results are consistent with the earlier results of Durand et al. (6), which were based on deletion analysis. They observed a 95 and $59 \%$ diminution in activation potential of an IL-2 promoter CAT construct after deleting 10 and 38 bases encompassing the proximal and distal octamer sites, respectively. The larger effects on transcription may be due to removal of additional factor-binding sequences within these deletions. Alternatively, the differences between their data and ours may be a consequence of examining enhancer mutation in the context of two different promoters, the IL-2 promoter in the investigations of Durand et al. and the fos promoter in our own studies. To clarify the larger effects of deletions in these regions, a more detailed mutational study, aimed at understanding the functional organization surrounding each octamer sequence, will be required.

The finding that each octamer site is important in achieving complete activation of the IL-2 gene suggests a potential function for the ubiquitous octamer protein in coordinating efficient signal transduction. Although the proximal octamer sequence is itself contained within a PHA-responsive element (6), simple multimerization of an octamer-binding site alone is insufficient to create a PHA-responsive element, because multimers encompassing the distal octamer sequence do not direct PHA-stimulated transcription (6). Therefore, other transcription factors independently, or in concert with Oct-1, probably account for the PHA responsiveness of the -65 to -95 DNA sequence in the IL-2 promoter. In fact, we have observed that a second factor, contained in nuclear extracts from both HeLa and Jurkat cells, binds a sequence just $5^{\prime}$ to the proximal octamer site (unpublished data). Mutational analysis can now be performed to clarify the activities of Oct-1 and this second factor in PHA-induced transcription.

\section{ACKNOWLEDGMENTS}

Mark Kamps is supported by The Damon Runyon-Walter Winchell Cancer Research Fund, grant DRG982, and Lynn Corcoran is supported by The Life Sciences Research Foundation. Jonathan LeBowitz is a Special Fellow of The Leukemia Society of America. This work was funded by Public Health Service grant GM 39458 from the National Institutes of Health.

\section{LITERATURE CITED}

1. Bergman, Y., D. Rice, R. Grosschedl, and D. Baltimore. 1984. Two regulatory elements for immunoglobulin $\mathrm{K}$ light chain gene expression. Proc. Natl. Acad. Sci. USA 81:7041-7045.

2. Bunses, D., H. Hardt, M. Rollinghuff, and A. Wagner. 1981. Cyclosporin A mediates immunosuppression of primary cytotoxic $T$ cell responses by impairing the release of interleukin-1 and interleukin-2. Eur. J. Immunol. 11:657-665.

3. Ciliberto, G., R. Buckland, R. Cortese, and L. Philipson. 1985. Transcription signals in embryonic Xenopus laevis U1 RNA genes. EMBO J. 4:1537-1543.

4. Dignam, J. D., R. M. Lebowitz, and R. G. Roeder. 1983.
Accurate transcription initiation by RNA polymerae II in a soluble extract from isolated mammalian nuclei. Nucleic Acids Res. 11:1475-1489.

5. Durand, D., M. Bush, J. Morgan, A. Weiss, and G. Crabtree. 1987. A 275 basepair fragment at the $5^{\prime}$ end of the interleukin 2 gene enhances expression from a heterologous promoter in response to signals from the $\mathrm{T}$ cell antigen receptor. J. Exp. Med. 165:395-407.

6. Durand, D., J. Shaw, M. Bush, R. Replogle, R. Belagaje, and G. Crabtree. 1988. Characterization of antigen receptor response elements within the interleukin-2 enhancer. Mol. Cell. Biol. 8:1715-1724.

7. Falkner, F., and H. Zachau. 1984. Correct transcription of an immunoglobulin $\mathrm{K}$ gene requires an upstream fragment containing conserved sequence elements. Nature (London) 310:71-74.

8. Fletcher, C., N. Heintz, and R. Roeder. 1987. Purification and characterization of OTF-1, a transcription factor regulating cell cycle expression of a human histone $\mathrm{H} 2 \mathrm{~b}$ gene. Cell 51:773-781.

9. Foster, J., J. Stafford, and C. Queen. 1985. An immunoglobulin promoter displays cell-type specificity independently of the enhancer. Nature (London) 315:423-425.

10. Fujita, T., H. Shibuya, T. Ohashi, K. Yamanishi, and T. Taniguchi. 1986. Regulation of human interleukin-2 gene: functional DNA sequences in the 5 ' flanking region for the gene expression in activated $T$ lymphocytes. Cell 46:401-407.

11. Fujita, T., C. Takaoka, H. Matsui, and T. Taniguchi. 1983. Structure of the human interleukin 2 gene. Proc. Natl. Acad. Sci. USA 80:7437-7441.

12. Gillis, S., and F. Watson. 1980. Biochemical and biological characterization of lymphocyte regulatory molecules. J. Exp. Med. 152:1709-1719.

13. Grosschedl, R., and D. Baltimore. 1985. Cell-type specificity of immunoglobulin gene expression is regulated by at least three DNA sequence elements. Cell 41:885-897.

14. Imboden, J., A. Weiss, and J. Stobo. 1985. The antigen receptor on a human $\mathrm{T}$ cell line initiates activation by increasing cytoplasmic free calcium. J. Immunol. 134:663-665.

15. Jones, K. A., K. R. Yamamoto, and R. Tijan. 1985. Two distinct transcription factors bind to the HSV thymidine kinase promoter in vitro. Cell 42:559-572.

16. Kristie, T. M., J. H. LeBowitz, and P. A. Sharp. 1989. The octamer-binding protein forms multi-protein-DNA complexes with the HSV $\alpha$ TIF regulatory protein. EMBO J. 8:4229-4238.

17. LeBowitz, J. H., R. G. Clerc, M. Brenowitz, and P. A. Sharp. 1989. The Oct-2 protein binds cooperatively to adjacent octamer sites. Genes Dev. 3:1624-1638.

18. Lenardo, M., J. W. Pierce, and D. Baltimore. 1987. Proteinbinding sites in Ig gene enhancers determine transcriptional activity and inducibility. Science 236:1573-1577.

19. Lotz, M., F. Jirik, P. Kabouridis, C. Tsoukas, T. Hirano, T. Kishimoto, and D. Carson. 1988. B cell stimulating factor 2 /interleukin 6 is a costimulant for human thymocytes and $T$ lymphocytes. J. Exp. Med. 167:1253-1258.

20. Mattaj, I., S. Lienhard, J. Jiricny, and E. De Robertis. 1985. An enhancer-like sequence within the Xenopus U2 gene promoter facilitates the formation of stable transcription complexes. Nature (London) 316:163-167.

21. Maxam, A., and W. Gilbert. 1980. Sequencing end-labeled DNA with base-specific chemical cleavages. Methods Enzymol. 65: 449-560.

22. Meuer, S., R. Hussey, D. Cantrell, J. Hodgdon, S. Schlossman, K. Smith, and E. Reinherz. 1984. Triggering of the T3-Ti antigen-receptor complex results in clonal $\mathrm{T}$-cell proliferation through an interleukin 2-dependent autocrine pathway. Proc. Natl. Acad. Sci. USA 81:1509-1513.

23. Muller, M. M., S. Ruppert, W. Schaffner, and P. Matthias. 1988. A cloned octamer transcription factor stimulates transcription from lymphoid specific promoters in non-B cells. Nature (London) 336:544-551.

24. Murphy, J., R. Burgess, J. Dahlberg, and E. Lund. 1982. Transcription of a gene for human U1 small nuclear RNA. Cell 29:265-274.

25. Nabel, G., C. Gorka, and D. Baltimore. 1988. T-cell-specific 
expression of interleukin 2: evidence for a negative regulatory site. Proc. Natl. Acad. Sci. USA 85:2934-2938.

26. Neefe, J., G. Curl, and J. Woody. 1981. Absolute requirement for adherent cells in the production of human interleukin 2 (IL-2). Cell. Immunol. 63:71-80.

27. O'Hare, P., and C. Goding. 1988. Herpes simplex virus regulatory elements and the immunoglobulin octamer domain bind a common factor and are both targets for virion transactivation. Cell 52:435-445.

28. Okada, M., M. Kitahara, S. Kishimoto, T. Matsuda, T. Hirano, and T. Kishimoto. 1988. IL-6/BSF-2 functions as a killer helper factor in the invitro induction of cytotoxic T cells. J. Immunol. 141:1543-1549.

29. Parslow, T., D. Blair, W. Murphy, and D. Granner. 1984. Structure of the 5 ' end of immunoglobulin genes: a novel conserved sequence. Proc. Natl. Acad. Sci. USA 81:2650-2654.

30. Picard, D., and W. Schaffiner. 1985. Cell-type preference of immunoglobulin $\mathrm{K}$ and 1 gene promoters. EMBO J. 4:28312838.

31. Schreiber, E., P. Matthias, M. Muller, and W. Schaffiner. 1988. Identification of a novel lymphoid specific octamer binding protein (OTF-2B) by proteolytic clipping bandshift assay (PCBA). EMBO J. 7:4221-4229.

32. Serfling, E., R. Barthelmas, I. Pfeuffer, B. Schenk, S. Zarius, R. Swoboda, F. Mercurio, and M. Karin. 1989. Ubiquitous and lymphocyte-specific factors are involved in the induction of the mouse interleukin 2 gene in T lymphocytes. EMBO J. 8:465473.

33. Shapiro, D., B. Adams, and J. Niederhuber. 1985. Antigenspecific $T$ cell activation results in an increase in cytoplasmic free calcium. J. Immunol. 135:2256-2261.

34. Shaw, J., P. Utz, D. Durand, J. Toole, E. Emmel, and G. Crabtree. 1988. Identification of a putative regulator of early $\mathrm{T}$ cell activation genes. Science 231:202-205.

35. Shibuya, H., and T. Taniguchi. 1989. Identification of multiple cis-elements and trans-acting factors involved in the induced expression of human IL-2 gene. Nucleic Acids Res. 17:91739184.

36. Siebenlist, U., D. Durand, P. Bressler, N. Holbrook, C. Norris, M. Kamoun, J. Kant, and G. Crabtree. 1986. Promoter region of interleukin-2 gene undergoes chromatin structure changes and confers inducibility on the chloramphenicol acetyltransferase gene during activation of T cells. Mol. Cell. Biol. 6:3042-3049.

37. Sive, H., N. Heintz, and R. Roeder. 1986. Multiple sequence elements are required for maximal in vitro transcription of a human histone H2B gene. Mol. Cell. Biol. 6:3329-3340.

38. Staudt, L. M., R. G. Clerc, H. Singh, J. H. LeBowitz, P. A. Sharp, and D. Baltimore. 1988. Cloning of a cDNA encoding a B-cell restricted octamer-binding factor. Science 241:577-580.

39. Tsien, R., T. Rozzan, and T. Rink. 1982. T-cell mitogens cause early changes in cytoplasmic free $\mathrm{Ca}$ and membrane potentials in lymphocytes. Nature (London) 295:68-71.

40. Weiss, A., J. Imboden, D. Shoback, and J. Stobo. 1984. Role of T3 surface molecules in human T-cell activation: T3-dependent activation results in an increase in cytoplasmic free calcium. Proc. Natl. Acad. Sci. USA 81:4169-4173.

41. Weiss, A., R. Wiskocil, and J. Stobo. 1984. The role of T3 surface molecules in the activation of human T cells: a twostimulus requirement for IL-2 production reflects events occurring at a pre-translational level. J. Immunol. 133:123-128.

42. Wirth, T., L. Staudt, and D. Baltimore. 1987. An octamer oligonucleotide upstream of a TATA motif is sufficient for lymphoid-specific promoter activity. Nature (London) 329:174 178.

43. Wiskocil, R., A. Weiss, J. Imboden, R. Kamin-Lewis, and J. Stobo. 1985. Activation of a human T cell line: a two stimulus requirement in the pretranslational events involved in the coordinate expression of interleukin 2 and gamma-interferon genes. J. Immunol. 134:1599-1603.

44. Zipfel, P. F., S. Irving, K. Kelly, and U. Siebenlist. 1989. Complexity of the primary genetic response to mitogenic activation of human T cells. Mol. Cell. Biol. 9:1041-1048. 